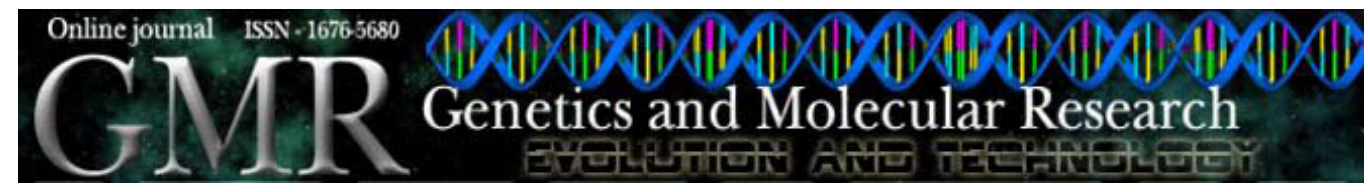

\title{
Mammaglobin and maspin transcripts in blood may reflect disease progression and the effect of therapy in breast cancer
}

\author{
O. Bitisik ${ }^{1}$, P. Saip ${ }^{2}$, S. Saglam ${ }^{2}$, D. Derin ${ }^{2}$ and N. Dalay ${ }^{1}$ \\ ${ }^{1}$ Department of Basic Oncology, Oncology Institute, \\ Istanbul University, Istanbul, Turkey \\ ${ }^{2}$ Department of Medical Oncology, Oncology Institute, \\ Istanbul University, Istanbul, Turkey \\ Corresponding author: N. Dalay \\ E-mail: ndalay@yahoo.com
}

Genet. Mol. Res. 9 (1): 97-106 (2010)

Received October 6, 2009

Accepted October 19, 2009

Published January 19, 2010

\begin{abstract}
Detection of residual tumor cells in the circulation can provide prognostic as well as therapeutic information and help in identifying patients at high risk for developing metastases. Maspin and mammaglobin are two molecules that are specifically associated with breast cancer. We looked for mammaglobin and maspin transcripts in the peripheral blood of patients with breast cancer and evaluated their utility as a marker of the response to therapy. Maspin and mammaglobin transcripts were analyzed in 85 breast-cancer patients by nested RT-PCR, prior to and after treatment. Before therapy, 10 patients were found positive for mammaglobin and 20 patients were positive for maspin. In four patients, both transcripts were de-
\end{abstract}


tected. Immediately following treatment, only one patient was still positive for mammaglobin while maspin transcripts persisted in three patients. Disease progression was observed mainly in patients in whom maspin transcripts were not detectable. Molecular detection of circulating tumor cells during therapy based on analysis for mammaglobin and maspin transcripts is an easy and practical method that can be applied to follow-up patients. We suggest that detection of mammaglobin mRNA is useful to determine the effect of therapy while maspin transcripts may indicate more aggressive disease.

Key words: Mammaglobin; Maspin; Breast cancer

\section{INTRODUCTION}

Breast carcinoma is the most frequent cancer among women, and early detection is one of the most crucial factors for a favorable outcome (Ballestrero et al., 2005). Currently, few diagnostic tools are available to identify the patients at risk, and there is a need for relevant independent prognostic and predictive factors with proven clinical utility to assess an individual patient's risk of disease recurrence (Stojadinovic et al., 2007; Gonzalez-Mancha et al., 2008). Early occult dissemination of tumor cells is one of the major causes of relapse after local treatment. Tumor cells in peripheral blood are capable of clonogenic growth in vitro, thus possibly participating in relapse (Sabbatini et al., 2000). Thus, the identification of circulating tumor cells in the peripheral blood of breast cancer patients can potentially provide important prognostic information and may have therapeutic implications. The development of sensitive approaches for the detection of residual tumor cells would also provide a valuable surveillance tool to evaluate the response to the therapy. In recent years, several highly sensitive methods have been developed to detect circulating cancer cells in the blood of patients with different types of malignancies. Reverse transcription-polymerase chain reaction (RT-PCR) provides a high analytical sensitivity to detect up to a single cancer cell among $10^{7}$ normal cells (Raj et al., 1998). Various molecular markers, including CEA, CK-19, Muc1, or CK-20, have been proposed to detect circulating breast cancer cells (Krismann et al., 1995; Bostick et al., 1998). However, most of these are poorly specific for tumor cells, and illegimate transcripts are occasionally detected in the blood, lymph nodes and bone marrow of healthy volunteers (Bae et al., 2000; Silva et al., 2001). Some earlier studies reporting the detection of circulating tumor cells have later been refuted, when it was shown that these molecular markers are also expressed by normal cells. Thus, these markers are not specific enough to be used for the detection of occult breast cancer cells (Corradini et al., 2001).

Moreover, breast tumors are composed of heterogenous cells with different levels of individual gene expression. Gene expression analysis provides a potentially easy and noninvasive approach, more accurate than existing markers and with prognostic relevance (Potemski et al., 2009). It has been suggested that the combination of different markers may eliminate some of the inherent problems associated with tumor heterogeneity. However, increasing the number of molecular markers may not necessarily increase clinical or diagnostic utility. Concordantly, it has been shown that multiple marker tests are not superior in sensitivity and that two-marker tests are a suitable approach to this 
issue (Fabisiewicz et al., 2004).

The mammaglobin gene (hMAM) is located on chromosome 11q13 and encodes a glycoprotein (Watson and Fleming, 1996). hMAM expression has been reported in 70-80\% of primary and metastatic breast tumors and has been associated with unfavorable prognosis (Min et al., 1998; Leygue et al., 1999). Expression of hMAM is restricted to breast epithelial cells. Due to this exclusive expression in breast tissue hMAM is a promising marker of interest in breast cancer.

Maspin is a $42-\mathrm{kDa}$ cytoplasmic protein belonging to the serpin family of serine protease inhibitors (Zhang, 2004). Numerous studies have implicated maspin function in cancer progression and angiogenesis (Zou et al., 1994). It has been shown to act as a tumor suppressor, and it is able to inhibit breast cancer cell motility, invasion and metastasis (Sheng et al., 1996). Surprisingly, the expression of maspin has been frequently observed in carcinoma cells with an aggressive phenotype (Yoshihisa et al., 2002), and it has been suggested that maspin plays a role in apoptosis (Khalkhali-Ellis and Hendrix, 2003) and breast cancer metastasis (Shi et al., 2003). Tamoxifen has also been shown to induce maspin promoter activity, a new mechanism associated with the clinical efficacy of the drug (Khalkhali-Ellis et al., 2004). Thus, detection of maspin may provide a putative molecular predictor of hormone responsiveness (Bieche et al., 2003). In contrast to other tissue-specific markers, mammaglobin and maspin are not detected in lymph nodes or blood samples from healthy donors (Luppi et al., 1996).

There are only a few studies in the literature investigating mammaglobin and maspin transcripts in the peripheral blood of patients. Their utility in predicting the efficiency of therapy has not been addressed yet. There is only a single study in the literature (Sabbatini et al., 2000) on the modulation of maspin expression in a small group of patients under treatment. Association of circulating mammaglobin transcripts with therapy has not been analyzed at all. In this study, we aimed to investigate the detection of mammaglobin and maspin transcripts in peripheral blood of breast cancer patients and to evaluate their potential as markers for the prediction of response to therapy.

\section{MATERIAL AND METHODS}

Peripheral blood samples from 85 patients with histologically confirmed breast cancer (mean age: $50.7 \pm 10.1$ years) were analyzed before and after chemotherapy for hMAM and maspin transcripts by nested RT-PCR. All patients had undergone surgery for tumor resection. Blood samples from 28 healthy women (mean age: $51.2 \pm 11.4$ years) were used as the control group. The clinical characteristics of the patients are shown in Table 1. Twenty-nine patients received 4 cycles of $\mathrm{AC}\left(600 \mathrm{mg} / \mathrm{m}^{2}\right.$ cyclophosphamide, $60 \mathrm{mg} / \mathrm{m}^{2}$ Adriamycin) and $56 \mathrm{pa}-$ tients with higher risk of recurrence received 6 cycles of FAC $\left(500 \mathrm{mg} / \mathrm{m}^{2}\right.$ cyclophosphamide, $50 \mathrm{mg} / \mathrm{m}^{2}$ Adriamycin, $500 \mathrm{mg} / \mathrm{m}^{2} 5$-fluorouracil). The median follow-up period after blood sampling was 48 (range 12-74) months.

Mononuclear cells were isolated by Ficoll-Histopaque (Sigma Chemicals Inc., St. Louis, USA) density gradient centrifugation and were homogenized in $1 \mathrm{~mL}$ Tritidy G reagent (Applichem, Darmstadt, Germany). Total cellular RNA was extracted according to manufacturer instructions. RNA quality was examined electrophoretically on a $1.5 \%$ agarose gel. 


\begin{tabular}{lc}
\multicolumn{2}{l}{ Table 1. Clinicopathological features of patients with breast cancer. } \\
\hline Clinical data & No. of patients (\%) \\
\hline Age (years) & \\
$<50$ & $28(32.95 \%)$ \\
$50-60$ & $42(49.4 \%)$ \\
$>60$ & $15(17.65 \%)$ \\
Histology & $67(78.8 \%)$ \\
Invasive ductal cancer & $9(10.6 \%)$ \\
Invasive lobular cancer & $4(4.7 \%)$ \\
Ductal/lobular cancer & $5(5.9 \%)$ \\
Other & \\
T stage & $31(36.5 \%)$ \\
T1 & $43(50.6 \%)$ \\
T2 & $9(10.6 \%)$ \\
T3 & $2(2.3 \%)$ \\
T4 & $28(32.95 \%)$ \\
Number of positive lymph nodes & $34(50.6 \%)$ \\
0 & $18(10.6 \%)$ \\
$1-3$ & $5(5.95 \%)$ \\
$4-10$ & $3(3.5 \%)$ \\
$>10$ & $37(43.5 \%)$ \\
Grade & $43(50.6 \%)$ \\
1 & $2(2.4 \%)$ \\
2 & \\
3 &
\end{tabular}

cDNA was synthesized from $1 \mu \mathrm{g}$ RNA using the Improm II Reverse Transcription System (Promega, Madison, USA) in a reaction mixture containing $5 \mathrm{X}$ reaction buffer, 2 $\mathrm{mM} \mathrm{MgCl}, 0.5 \mathrm{mM}$ deoxynucleotide triphosphate (dNTP), $0.5 \mu \mathrm{g} / \mu \mathrm{L}$ random primer, $20 \mathrm{U}$ ribonuclease inhibitor and $1 \mu \mathrm{L}$ reverse trancriptase. The mixture was incubated for $5 \mathrm{~min}$ at $25^{\circ} \mathrm{C}$ for annealing, extension was performed for $1 \mathrm{~h}$ at $42^{\circ} \mathrm{C}$, and termination was at $4^{\circ} \mathrm{C}$ for 5 min. The quality of RNA and cDNA synthesis and absence of inhibitors was ascertained by amplification of the G6PDH gene as internal control.

The primer sequences used in the study are listed in Table 2. PCR for mammaglobin was carried out in $50 \mu \mathrm{L}$ final volume using $3 \mu \mathrm{L}$ cDNA, $5 X$ PCR buffer, $1.5 \mathrm{mM} \mathrm{MgCl}, 0.5$ $\mathrm{mM}$ of each dNTP, $20 \mathrm{ng}$ of each of the outer primers and $1 \mathrm{U}$ Taq DNA polymerase. The reaction was begun by incubation for $5 \mathrm{~min}$ at $95^{\circ} \mathrm{C}$, followed by 35 cycles of denaturation at $95^{\circ} \mathrm{C}$ for $40 \mathrm{~s}$, annealing at $55^{\circ} \mathrm{C}$ for $40 \mathrm{~s}$, and extension at $72^{\circ} \mathrm{C}$ for $40 \mathrm{~s}$. For the second round of PCR, $1 \mu \mathrm{L}$ of the first round PCR product was used in combination with $20 \mathrm{ng}$ hMAM-IF and hMAM-IR inner primers in $50 \mu \mathrm{L}$ final volume. The cycling and reaction conditions were the same. The outer and inner primer pairs for the mammaglobin transcripts yielded products of 402 and $367 \mathrm{bp}$, respectively.

\begin{tabular}{|c|c|c|}
\hline Primer & Sequence & Product size (bp) \\
\hline hMAM-OF & 5'-CAG CGG CTT CCT TGA TCC TTG-3' & 402 bp \\
\hline hMAM-OR & 5'-ATA AGA AAG AGA AGG TGT GG-3' & \\
\hline hMAM-IF & 5'-TGA ACA CCG ACA GCA GCA G-3' & $367 \mathrm{bp}$ \\
\hline hMAM-IR & 5'-TCC GTA GTT GGT TTC TCA CC-3' & \\
\hline Mas-OF & 5'-TCA AGC GGC TCT ACG TAG AC-3' & $447 \mathrm{bp}$ \\
\hline Mas-OR & 5'-СCТ CCA CAT CCT TGG GTA GT-3' & \\
\hline Mas-IF & 5'-GAT CTC ACA GAT GGC CAC TT-3' & $175 \mathrm{bp}$ \\
\hline Mas-IR & 5'-GCA CTG GTT TGG TGT CTG TC-3' & \\
\hline
\end{tabular}


To investigate the maspin (Mas) transcripts, $3 \mu \mathrm{L}$ cDNA was added to $50 \mu \mathrm{L}$ reaction mixture as described above. Denaturation at $95^{\circ} \mathrm{C}$ for 5 min was followed by 35 cycles of denaturation at $95^{\circ} \mathrm{C}$ for $40 \mathrm{~s}$, annealing at $58^{\circ} \mathrm{C}$ for $40 \mathrm{~s}$, and extension at $72^{\circ} \mathrm{C}$ for $40 \mathrm{~s}$. For the second round PCR, $1 \mu \mathrm{L}$ of the PCR product was used in combination with $20 \mathrm{ng}$ Mas-IF and Mas-IR primers in $50 \mu \mathrm{L}$ final volume. The cycling and reaction conditions were the same. The primer pairs for the maspin transcripts yielded products of 447 and $175 \mathrm{bp}$.

The PCR products were electrophoresed on $2 \%$ agarose gels and evaluated using a gel documentation system (Vilber-Lourmat, Marné a Vallée, France) after staining with ethidium bromide. The sensitivity of the RT-PCR assay was controlled by dilution of the RNA samples. In 10 representative tumor samples, the presence of mammaglobin and maspin RNA transcripts was successfully and reproducibly detected up to a dilution of $10^{-6}\left(10^{-7}\right.$ in four samples).

Statistical calculations were performed using the chi-square test. Kaplan-Meier and $\log$ rank tests were used for survival analysis.

\section{RESULTS}

We investigated mammaglobin and maspin mRNAs as markers for the detection of carcinoma cells by RT-PCR and for the effects of systemic chemotherapy, in the peripheral blood of breast cancer patients. Representative examples of hMAM and maspin products detected in sera are shown in Figures 1 and 2, respectively. All healthy controls were negative for hMAM and maspin mRNAs. Prior to therapy, 10 patients were positive for hMAM (proportion: 11.76 ; 95\% CI: 5.79-20.57) and 20 patients were positive for maspin mRNA (proportion: 23.5; 95\%CI: 15.0-33.97) (Table 3). In 4 patients (4.7\%), both transcripts were detected.

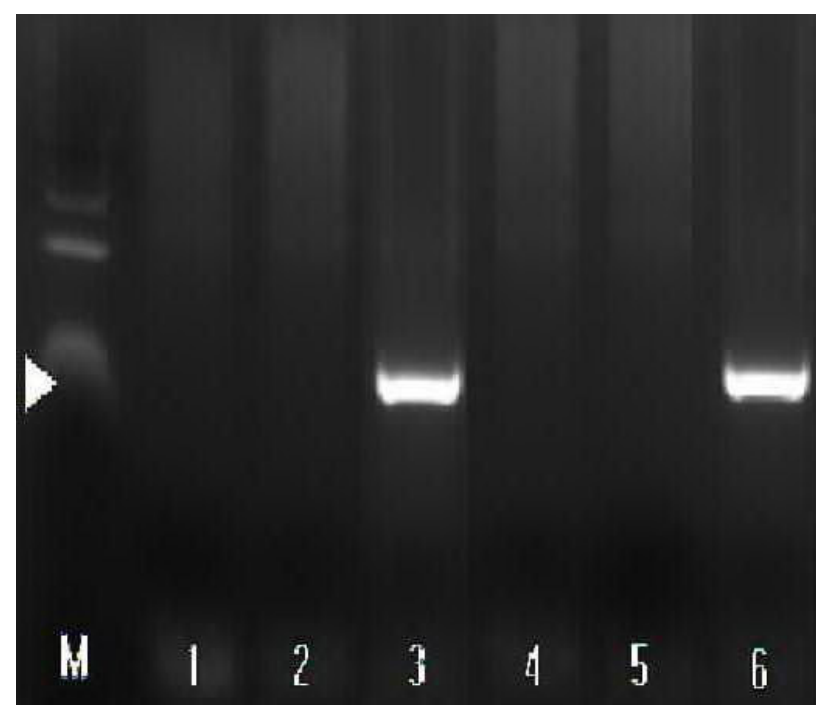

Figure 1. Ethidium bromide staining of an agarose gel showing nested RT-PCR analysis of mammaglobin mRNA expression in peripheral blood of breast cancer patients. M: Molecular weight marker (QX174/HaeIII); lanes 3, 6: mammaglobin-positive samples; lanes 1, 2, 4: mammaglobin-negative samples; lane 5: negative control. 


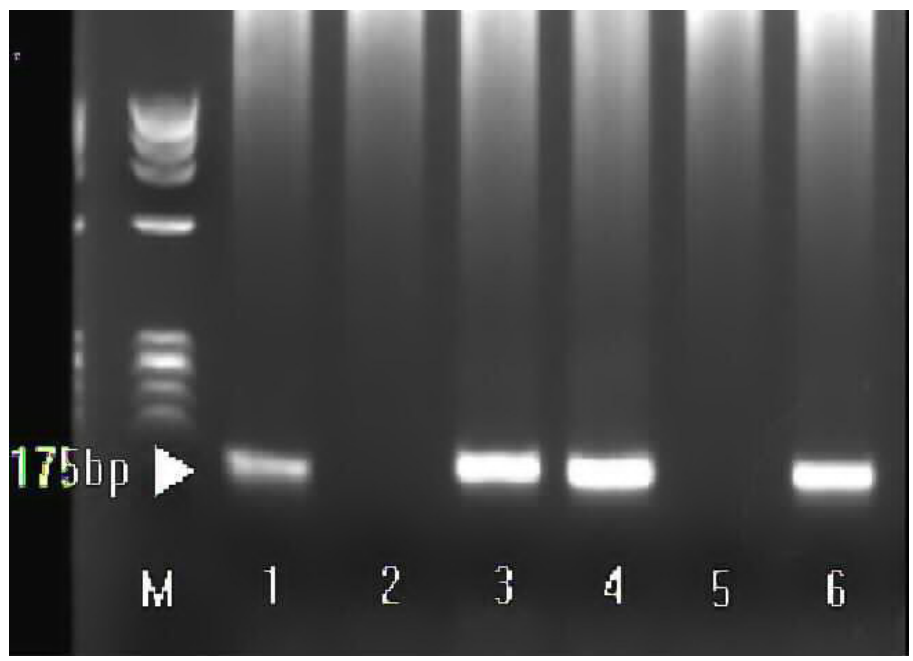

Figure 2. Analysis of maspin mRNA in peripheral blood of breast cancer patients. $M$ : Molecular weight marker (QX174/HaeIII); lanes 1, 3, 4, 6: maspin-positive samples; lane 2: maspin-negative sample; lane 5: negative control.

Table 3. Mammaglobin and maspin transcripts in the patients.
\begin{tabular}{lcc} 
& Before treatment & After treatment \\
\hline Mammaglobin & $10(11.7 \%)$ & $1(1.2 \%)$ \\
Maspin & $20(23.5 \%)$ & $3(8.2 \%)$ \\
\hline
\end{tabular}

Data are reported as number of patients with percent in parentheses.

Following treatment, only one patient remained positive for hMAM (proportion: 1.18; 95\% CI: 0.03-6.38) and 3 patients remained positive for maspin mRNAs (proportion: 8.24; 95\% CI: 3.38-16.23). The cumulative probability of positivity before and after treatment was $30.5 \%$ for mammaglobin and $21.2 \%$ for maspin. Following therapy, mammaglobin transcripts were observed in 9 patients and three of these developed metastases. However, the difference was not significant. Among the patients who had tested negative before chemotherapy, mammaglobin transcripts were detected in 9 patients, and maspin transcripts were detected in 7 patients, following treatment. No association was observed between mammaglobin or maspin expression in the two different chemotherapy regimens.

After a median follow-up of 48 months, disease progression was observed in 18 patients. In these patients, maspin transcripts were either completely absent at any stage or had been positive before therapy but disappeared during treatment. Progressive disease was observed in 11 patients in whom maspin transcrips were initially present but disappeared after therapy (Table 4). This difference was highly significant $(\mathrm{P}<0.004)$. No statistically significant correlation between maspin or mammaglobin positivity and clinical parameters were found including age, stage of disease, histological type, estrogen and progesterone receptor status, presence of metastasis on admission and location of the tumor. The survival analysis revealed no association with PCR positivity for either transcript. 


\begin{tabular}{lcc} 
Table 4. Distribution of mammaglobin- and maspin-positive patients with disease progression. \\
\hline & Before treatment & After treatment \\
\hline Mammaglobin & $3(16.6 \%)$ & $4(22.2 \%)$ \\
Maspin & $11(61.1 \%)$ & $0-$ \\
\hline
\end{tabular}

Data are reported as number of patients with percent in parentheses.

\section{DISCUSSION}

The detection of tumor-associated circulating markers in peripheral blood may be useful for prognostic and therapeutic implications. Association of these with possible dissemination and the therapeutic response remains an important area of research. A blood test for circulating tumor cells provides a promising approach for the early prediction of therapeutic efficacy.

There are a number of markers widely used to identify circulating tumor cells; however, most of these molecules are also detected in the peripheral blood of healthy volunteers. Specificity of the RT-PCR techniques is abrogated when the mRNA marker is expressed by normal hematopoietic cells (Corradini et al., 2001). Furthermore, during chemotherapy, normal proliferating cells are also damaged by cytotoxic drugs and may contribute to the release of these molecules. Therefore, any marker to be used to evaluate the therapeutic effect should be highly specific for tumor cells. Mammaglobin and maspin are two putative breast tissuespecific markers frequently used for detection of occult tumor cells in peripheral blood, bone marrow and lymph nodes of breast cancer patients (Ballestrero et al., 2005). There are no studies in the literature investigating their utility in evaluating response to therapy. The present study was undertaken to investigate the detection of mammaglobin and maspin transcripts in peripheral blood of patients with breast cancer and to evaluate the changes in response to chemotherapy.

Transcripts of both genes were detected by RT-PCR in the peripheral blood of breast cancer patients but not of healthy volunteers. We achieved a much higher sensitivity than in earlier reports using conventional RT-PCR (Sabbatini et al., 2000; Corradini et al., 2001; Stathopoulou et al., 2003). The specifity of mammaglobin and maspin for circulating tumor cells was very high $(100 \%)$ due to the preselection and enrichment by the two-step nested approach used; however, the sensitivity of hMAM was considerably lower (11.8\%) when compared to maspin $(23.5 \%)$. These data are in agreement with a very recent report in which similar rates of positivity at comparable specificity were found for mammaglobin (7\%) and maspin (24\%) transcripts in untreated breast cancer (Mercatali et al., 2006). We observed no difference for mammaglobin or maspin expression in response to the addition of 5-FU to the chemothrerapy regimen. This issue has not been investigated so far, and to date no information is available on a possible effect of the chemotherapeutic drugs on mammaglobin or maspin expression other than a probably indirect apoptosis-sensitizing effect of maspin in head and neck cancer (Marioni et al., 2008) and ovarian carcinoma (Surowiak et al., 2006) patients treated with cisplatin-containing regimes. In these studies, elevated maspin expression has been associated with cisplatin resistance. Neither maspin nor mammaglobin has been associated with any other chemotherapeutic drug.

Lack of correlation between mammaglobin and maspin expression and clinical parameters is also consistent with previous findings (Suchy et al., 2000) as well as recent reports 
on breast (Marques et al., 2009), ovarian (Surowiak et al., 2006; Klasa-Mazurkiewicz et al., 2009) and laryngeal cancer (Marioni et al., 2008).

In our study, mammaglobin transcripts were observed in $11 \%$ of the patients. The positivity rate for mammaglobin is lower than that reported by two previous studies (Zach et al., 1999; Bossolasco et al., 2002).

This variation is in accordance with a report in which mammaglobin mRNA has been found to be the most specific molecular marker for hematogenous spread of breast cancer cells (Ntoulia et al., 2006) and can be explained by the small number of metastatic patients in our study population. hMAM transcripts have been detected in the peripheral blood of up to $25 \%$ of breast cancer patients when metastasis is present (Suchy et al., 2000; Bossolasco et al., 2002). While only $7 \%$ of the patients in our group had metastatic disease on admission, metastasis was present in 44 and $23.7 \%$ in the cohort of the above studies. The detection rate in non-metastatic patients at diagnosis and during follow-up was comparable to our data in the same reports ( 11.2 and $9 \%$, respectively). In our study, $33 \%$ of the patients with detectable mammaglobin transcripts after therapy developed metastases.

Maspin transcripts were observed in $23.5 \%$ of patients and in none of the controls. This rate is higher than in earlier reports (Sabbatini et al., 2000; Stathopoulou et al., 2003) but in accordance with recent data (Mercatali et al., 2006). The positivity rate for maspin expression is also in concordance with maspin expression in tumor tissue (Yoshihisa et al., 2002).

Following therapy, all patients initially positive for the mammaglobin transcript turned negative. This probably reflects the effects of systemic therapy on circulating tumor cells. Concordantly, the detection of late transcripts in patients who were negative in the beginning may be associated with disease progression. In accordance with this finding, a high incidence of relapses has been reported in the group of patients who displayed mammaglobin mRNA-positive cells in their blood (Ntoulia et al., 2006). An association between circulating CEA mRNA and higher risk of metastasis has also been reported recently for colon cancer patients (Wang et al., 2006).

Association between loss of maspin expression and progressive disease is in line with the role of maspin as a tumor suppressor and has been recently reported in malignant melanoma (Denk et al., 2007), head and neck cancer (Marioni et al., 2009) and ovarian cancer (Surowiak et al., 2006; Secord et al., 2006). In colorectal cancer patients, non-detectable maspin expression has been shown to increase the risk of disease progression and death 2-fold (Boltze et al., 2005). In seven patients who were negative on admission, maspin transcripts were detected after treatment. This may be due to the mobilization of tumor cells in response to cytotoxic treatment, as suggested by a recent study (Sabbatini et al., 2000). However, this report should be interpreted with caution due to the very small number of patients where only half were available for evaluation after therapy. Alternatively, exposure to specific cytokines may also induce maspin expression (Ballestrero et al., 2005). Recently, it has been reported that tamoxifen can also exert an inductive effect on the maspin promoter (Khalkhali-Ellis et al., 2004). However, none of the patients in our study received tamoxifen during the sampling period.

We have shown that this molecular assay can identify circulating tumor cells and may have predictive implications in evaluating the efficacy of treatment. Our data indicate that accurate molecular detection of circulating tumor cells based on the analysis of breast-specific mammaglobin and maspin genes in peripheral blood may provide a practical and rational approach for the surveillance of breast cancer patients during therapy. Although mammaglobin would not be useful as a classical tumor marker, monitoring mammaglobin mRNA levels may reflect the efficacy of the therapy. Disappearance of the maspin transcripts with chemotherapy 
might be associated with a higher risk of progression and possibly aggressive tumors. Further studies with larger series of patients and longer follow-up are needed to validate these results and to determine whether this assay will be useful in guiding clinical decisions.

\section{ACKNOWLEDGMENTS}

Research supported by the Istanbul University Research Fund (Projects \#13/27082002 and \#UDP-373/1008204).

\section{REFERENCES}

Bae JW, Choi KH, Kim HG and Park SH (2000). The detection of circulating breast cancer cells in peripheral blood by reverse transcriptase-polymerase chain reaction. J. Korean Med. Sci. 15: 194-198.

Ballestrero A, Garuti A, Bertolotto M, Rocco I, et al. (2005). Effect of different cytokines on mammaglobin and maspin gene expression in normal leukocytes: possible relevance to the assays for the detection of micrometastatic breast cancer. Br. J. Cancer 92: 1948-1952.

Bieche I, Girault I, Sabourin JC, Tozlu S, et al. (2003). Prognostic value of maspin mRNA expression in ER alpha-positive postmenopausal breast carcinomas. Br. J. Cancer 88: 863-870.

Boltze C (2005). Loss of maspin is a helpful prognosticator in colorectal cancer: a tissue microarray analysis. Pathol. Res. Pract. 200: 783-790.

Bossolasco P, Ricci C, Farina G, Soligo D, et al. (2002). Detection of micrometastatic cells in breast cancer by RT-PCR for the mammaglobin gene. Cancer Detect. Prev. 26: 60-63.

Bostick PJ, Chatterjee S, Chi DD, Huynh KT, et al. (1998). Limitations of specific reverse-transcriptase polymerase chain reaction markers in the detection of metastases in the lymph nodes and blood of breast cancer patients. J. Clin. Oncol. 16: 2632-2640.

Corradini P, Voena C, Astolfi M, Delloro S, et al. (2001). Maspin and mammaglobin genes are specific markers for RTPCR detection of minimal residual disease in patients with breast cancer. Ann. Oncol. 12: 1693-1698.

Denk AE, Bettstetter M, Wild PJ, Hoek K, et al. (2007). Loss of maspin expression contributes to a more invasive potential in malignant melanoma. Pigment Cell Res. 20: 112-119.

Fabisiewicz A, Kulik J, Kober P, Brewczynska E, et al. (2004). Detection of circulating breast cancer cells in peripheral blood by a two-marker reverse transcriptase-polymerase chain reaction assay. Acta Biochim. Pol. 51: 747-755.

Gonzalez-Mancha R, Galan JJ, Crespo C, Iglesias PL, et al. (2008). Analysis of the ERalpha germline PvuII marker in breast cancer risk. Med. Sci. Monit. 14: CR136-CR143.

Khalkhali-Ellis Z and Hendrix MJ (2003). Nitric oxide regulation of maspin expression in normal mammary epithelial and breast cancer cells. Am. J. Pathol. 162: 1411-1417.

Khalkhali-Ellis Z, Christian AL, Kirschmann DA, Edwards EM, et al. (2004). Regulating the tumor suppressor gene maspin in breast cancer cells: a potential mechanism for the anticancer properties of tamoxifen. Clin. Cancer Res. 10: 449-454.

Klasa-Mazurkiewicz D, Narkiewicz J, Milczek T, Lipinska B, et al. (2009). Maspin overexpression correlates with positive response to primary chemotherapy in ovarian cancer patients. Gynecol. Oncol. 113: 91-98.

Krismann M, Todt B, Schroder J, Gareis D, et al. (1995). Low specificity of cytokeratin 19 reverse transcriptase-polymerase chain reaction analyses for detection of hematogenous lung cancer dissemination. J. Clin. Oncol. 13: 2769-2775.

Leygue E, Snell L, Dotzlaw H, Hole K, et al. (1999). Mammaglobin, a potential marker of breast cancer nodal metastasis. J. Pathol. 189: 28-33.

Luppi M, Morselli M, Bandieri E, Federico M, et al. (1996). Sensitive detection of circulating breast cancer cells by reverse-transcriptase polymerase chain reaction of maspin gene. Ann. Oncol. 7: 619-624.

Marioni G, Giacomelli L, D’Alessandro E, Marchese-Ragona R, et al. (2008). Nuclear localization of mammary serine protease inhibitor (MASPIN): is its impact on the prognosis in laryngeal carcinoma due to a proapoptotic effect? $\mathrm{Am}$. J. Otolaryngol. 29: 156-162.

Marioni G, Koussis H, Gaio E, Giacomelli L, et al. (2009). MASPIN's prognostic role in patients with advanced head and neck carcinoma treated with primary chemotherapy (carboplatin plus vinorelbine) and radiotherapy: preliminary evidence. Acta Otolaryngol. 129: 786-792.

Marques AR, Teixeira E, Diamond J, Correia H, et al. (2009). Detection of human mammaglobin mRNA in serial peripheral blood samples from patients with non-metastatic breast cancer is not predictive of disease recurrence. Breast Cancer Res. Treat. 114: 223-232. 
Mercatali L, Valenti V, Calistri D, Calpona S, et al. (2006). RT-PCR determination of maspin and mammaglobin B in peripheral blood of healthy donors and breast cancer patients. Ann. Oncol. 17: 424-428.

Min CJ, Tafra L and Verbanac KM (1998). Identification of superior markers for polymerase chain reaction detection of breast cancer metastases in sentinel lymph nodes. Cancer Res. 58: 4581-4584.

Ntoulia M, Stathopoulou A, Ignatiadis M, Malamos N, et al. (2006). Detection of mammaglobin A-mRNA-positive circulating tumor cells in peripheral blood of patients with operable breast cancer with nested RT-PCR. Clin. Biochem. 39: 879-887.

Potemski P, Kusinska R, Pasz-Walczak G, Piekarski JH, et al. (2009). Prognostic relevance of cyclin E expression in operable breast cancer. Med. Sci. Monit. 15: MT34-MT40.

Raj GV, Moreno JG and Gomella LG (1998). Utilization of polymerase chain reaction technology in the detection of solid tumors. Cancer 82: 1419-1442.

Sabbatini R, Federico M, Morselli M, Depenni R, et al. (2000). Detection of circulating tumor cells by reverse transcriptase polymerase chain reaction of maspin in patients with breast cancer undergoing conventional-dose chemotherapy. $J$. Clin. Oncol. 18: 1914-1920.

Secord AA, Lee PS, Darcy KM, Havrilesky LJ, et al. (2006). Maspin expression in epithelial ovarian cancer and associations with poor prognosis: a Gynecologic Oncology Group Study. Gynecol. Oncol. 101: 390-397.

Sheng S, Carey J, Seftor EA, Dias L, et al. (1996). Maspin acts at the cell membrane to inhibit invasion and motility of mammary and prostatic cancer cells. Proc. Natl. Acad. Sci. USA 93: 11669-11674.

Shi HY, Zhang W, Liang R, Kittrell F, et al. (2003). Modeling human breast cancer metastasis in mice: maspin as a paradigm. Histol. Histopathol. 18: 201-206.

Silva AL, Diamond J, Silva MR and Passos-Coelho JL (2001). Cytokeratin 20 is not a reliable molecular marker for occult breast cancer cell detection in hematological tissues. Breast Cancer Res. Treat. 66: 59-66.

Stathopoulou A, Mavroudis D, Perraki M, Apostolaki S, et al. (2003). Molecular detection of cancer cells in the peripheral blood of patients with breast cancer: comparison of CK-19, CEA and maspin as detection markers. Anticancer Res. 23: 1883-1890.

Stojadinovic A, Hooke JA, Shriver CD, Nissan A, et al. (2007). HYOU1/Orp150 expression in breast cancer. Med. Sci. Monit. 13: BR231-BR239.

Suchy B, Austrup F, Driesel G, Eder C, et al. (2000). Detection of mammaglobin expressing cells in blood of breast cancer patients. Cancer Lett. 158: 171-178.

Surowiak P, Materna V, Drag-Zalesinska M, Wojnar A, et al. (2006). Maspin expression is characteristic for cisplatinsensitive ovarian cancer cells and for ovarian cancer cases of longer survival rates. Int. J. Gynecol. Pathol. 25: 131-139.

Wang JY, Wu CH, Lu CY, Hsieh JS, et al. (2006). Molecular detection of circulating tumor cells in the peripheral blood of patients with colorectal cancer using RT-PCR: significance of the prediction of postoperative metastasis. World J. Surg. 30: 1007-1013.

Watson MA and Fleming TP (1996). Mammaglobin, a mammary-specific member of the uteroglobin gene family, is overexpressed in human breast cancer. Cancer Res. 56: 860-865.

Yoshihisa U, Yasuyo O, Yoshiatsu S and Hiroki Y (2002). Expression of maspin predicts poor prognosis in breast cancer patients. Int. J. Cancer 100: 452-455.

Zach O, Kasparu H, Krieger O, Hehenwarter W, et al. (1999). Detection of circulating mammary carcinoma cells in the peripheral blood of breast cancer patients via a nested reverse transcriptase polymerase chain reaction assay for mammaglobin mRNA. J. Clin. Oncol. 17: 2015-2019.

Zhang M (2004). Multiple functions of maspin in tumor progression and mouse development. Front. Biosci. 9: 2218-2226.

Zou Z, Anisowicz A, Hendrix MJ, Thor A, et al. (1994). Maspin, a serpin with tumor-suppressing activity in human mammary epithelial cells. Science 263: 526-529. 